\title{
Association between regulatory $T$ cell activity and sepsis and outcome of severely burned patients: a prospective, observational study
}

\author{
Li-feng Huang, Yong-ming Yao*, Ning Dong, Yan Yu, Li-xin He and Zhi-yong Sheng
}

\begin{abstract}
Introduction: To investigate the significance of changes in regulatory T cells (Tregs) activity and its relationship with sepsis, as well as outcome of patients with major burns.

Methods: The periphery blood samples of 106 patients were collected on post-burn days 1, 3, 7, 14, and 21. Tregs were isolated and their phenotypes (cytotoxic T-lymphocyte-associated antigen 4 and forkhead/winged helix transcription factor p3) were analyzed by flow cytometry, and the contents of cytokines (interleukin-10 and transforming growth factor- $\beta 1$ ) released into supernatants by Tregs were also determined by enzyme-linked immunosorbent assay kits. Gene expressions of cytokines were assessed by real-time quantitative polymerase chain reaction.

Results: Expressions of Tregs phenotypes and gene/protein expression of cytokines were all elevated after burn, and there were obvious differences among patients with various burn sizes. They were also higher in septic patients than those without sepsis. Among septic patients, the expressions of Tregs phenotypes and the levels of cytokines were markedly lower in the survival group than those in patients with fatal outcome.

Conclusions: Severe burn injury per se could lead to the changes in Tregs activities. Elevated levels of cytokines produced by Tregs and activation markers on Tregs surface might play an important role in the pathogenesis of sepsis and mortality in burned patients.
\end{abstract}

\section{Introduction}

There is accumulating evidence indicating that regulatory $\mathrm{T}$ cells (Tregs) play important roles in the maintenance of immunologic self-tolerance and in down-regulation of various immune responses [1]. Tregs have been shown to be important in regulating the immune responses in transplant rejection, tumor immunity, infectious diseases and allergy. Thus, there has recently been an increasing interest in investigating the biology of Tregs as well as its potential application in the treatment of immunity relevant illnesses.

Many types of Treg subsets have been reported in a variety of morbid conditions. It is now clear that immune regulatory cells consist of many distinct $\mathrm{T}$ cell subsets [2]. Among them, $\mathrm{CD}^{+}$Tregs have been demonstrated in a wide range of animal models and in humans $[3,4]$, and the

*Correspondence: c_ff@sina.com

1 Department of Microbiology and Immunology, Burns Institute, First Hospital Affiliated to the Chinese PLA General Hospital, 51 Fu-cheng Road, Haidian District, Beijing 100048, PR China forkhead/winged helix transcription factor $\mathrm{p} 3$ (FOXP3) has been suggested to represent a reliable intracellular marker for naturally occurring Tregs [5]. Most studies on $\mathrm{CD}^{+}$ Tregs use a combination of CD25, cytotoxic T-lymphocyteassociated antigen 4 (CTLA-4), FOXP3, IL-10 and/or transforming growth factor- $\beta 1$ (TGF- $\beta 1$ ) to define Treg populations [6].

The stress response to burn injury is similar to that of severe trauma or critical illness but differs in its severity and duration. The inflammatory response is triggered immediately after thermal injury and persists for almost five weeks postburn [7]. Superimposed severe infections can result in the suppression of one or more functions of the host immune system after major burns. Multiple mechanisms have been proposed to explain infection-induced immunosuppression, including an imbalance in the cellular $\mathrm{T}$ helper cell (Th1/Th2) or cytokine profile, induction of anergy, depletion of effector cells and most recently the activation of $\mathrm{CD}^{+}{ }^{+} \mathrm{CD} 25^{+}$Tregs [8]. The role of both natu-

(c) 2010 Huang et al.; licensee BioMed Central Ltd. This is an open access article distributed under the terms of the Creative Commons :HW 1 ed Central Attribution License (http://creativecommons.org/licenses/by/2.0), which permits unrestricted use, distribution, and reproduction in any medium, provided the original work is properly cited. 
rally occurring $\mathrm{CD} 4{ }^{+} \mathrm{CD} 25^{+}$Tregs and IL-10-secreting Tregs in infection has been the subject of several recent excellent reviews [9,10]. However, it seems that its response to trauma, burns, hemorrhagic shock, and microbial infection is associated with only a transient proinflammatory period followed by a more prolonged period of immune suppression [11]. Thus, it is speculated that there are some other factors involved in this process.

Numerous studies show that an increased burn size leads to higher mortality of burned patients $[12,13]$. It was also implicated that the extent of burn size might be associated with the development of sepsis. It is now believed that along with the body's hyperinflammatory response designated to eliminate the invading pathogen, mechanisms primarily aimed at controlling this initial response are initiated, but may turn out to be deleterious with immune dysfunctions and even death. A similar state of immune suppression has been described after numerous forms of severe trauma [14-16].

Although more and more evidence for immune dysfunction after sepsis has been accumulated the mechanisms underlying its development and how it acts to worsen the morbid state of the critically ill patient are yet to be elucidated. In this context, although the majority of clinical and basic researches conducted so far have focused on the roles of myeloid cell populations [17], the contribution of T lymphocytes $[18,19]$ and, in particular, of Tregs has been somewhat ignored. Whether $\mathrm{CD} 4{ }^{+} \mathrm{CD} 25^{+}$Tregs participate directly in sepsis-induced immunoparalysis resulting in poor outcomes remains to be investigated. The purpose of the present study was to investigate the significance of changes in activity of Tregs in severely burned patients, and its relation with pathogenesis of sepsis as well as the outcome of the patients following major burns.

\section{Materials and methods \\ Participants and demography}

One hundred and six patients who were admitted to our burns unit with total burn surface area (TBSA) larger than $30 \%$ were included in the present study over a time period of 10 months. Patients were resuscitated according to the Parkland formula using colloid and Ringer's lactate. Within 48 hours of admission all patients had undergone most burn wound excision for full-thickness burns, and the excision wounds were covered with available autologous skin, and allograft was used to cover any remaining open wounds. Five to ten days after healing of the donor area, the remaining wounds were totally covered with autograft skin.

The thermally injured patients were stratified into three groups according to burn size: 30 to $49 \%$ TBSA burns (group I, $\mathrm{n}=41$ ), 50 to $69 \%$ TBSA burns (group II, $\mathrm{n}=34$ ), and more than $70 \%$ TBSA burns (group III, $\mathrm{n}=31$ ). According to whether there was development of sepsis or not, patients were divided into sepsis group $(\mathrm{n}=59)$ and non-sepsis group based on the criteria for definition of severe sepsis [20] $(\mathrm{n}=47)$; then the patients with sepsis were further divided into non-survival group $(n=17)$ and survival group $(n=42)$. Twenty-five healthy volunteers served as normal controls (17 men and 8 women, mean age $28.6 \pm 6.2$ years, range 21 to 45 years). The periphery blood samples were collected on postburn days (PBD) 1, 3, 7, 14, and 21 . The study was reviewed and approved by the Institutional Review Board of the Burns Institute, First Hospital Affiliated to the Chinese PLA General Hospital, Beijing, China. Prior to the study, each patient or the patient's legal guardian signed a written informed consent form.

\section{Reagents and kits}

RPMI 1640, FCS, glutamine, penicillin, streptomycin, and HEPES were purchased from TianRunShanda Biotech Co. Ltd (Beijing, China). Human $\mathrm{CD} 4{ }^{+} \mathrm{CD} 25^{+}$Tregs isolation kit and human fluorescein isothiocyanate (FITC)-conjugated anti-human CD4 (IgG1, Clone M-T466) were purchased from Miltenyi Biotec $\mathrm{GmbH}$ (Bergisch Gladbach, Germany). Antibodies used for flow cytometry analysis, including FITC-conjugated anti-human CD152 (CTLA-4, IgG2a, Clone 14D3), FITC-conjugated anti-human FOXP3 (IgG2a, $\kappa$. Clone PCH101) were purchased from eBioscience (San Diego, CA, USA). Total RNA isolation system and RT-PCR system were purchased from Promega (Madison, WI, USA). SYBR Green PCR Master MIX was purchased from Applied Biosystems (Foster City, CA, USA). ELISA kits of human IL-10 and TGF- $\beta 1$ were purchased from Biosource (Worcester, MA, USA).

\section{Isolation of circulating Tregs}

In an EDTA test tube, $10 \mathrm{ml}$ of venous blood was collected. It was then diluted in Hanks' balanced salt solution, and Ficoll-Hypaque (Sigma Chemical Co., St. Louis, MO, USA) was used for isolation and preparation of peripheral blood lymphocytes. After centrifugation, the sedimentary cells were collected. The cells were isolated using MicroBeads and a MiniMACS ${ }^{\mathrm{TM}}$ separator according to the manufacturer's instructions. $\mathrm{CD}^{+} \mathrm{T}$ cells were enriched by depletion of cells expressing CD8, CD14, CD16, CD19, CD36, CD56, CD123, TCR $\gamma / \delta$ and CD235a from lymphocytes with a $\mathrm{CD} 4{ }^{+} \mathrm{CD} 25^{+}$Regulatory $\mathrm{T}$ Cell Isolation Kit. $\mathrm{CD} 4{ }^{+} \mathrm{CD} 25^{+}$Tregs and $\mathrm{CD} 4{ }^{+} \mathrm{CD} 25^{-} \mathrm{T}$ cells were further selected according to the expression of CD25. The purity of isolated Tregs and $\mathrm{CD}^{+}{ }^{+} \mathrm{CD} 25^{-} \mathrm{T}$ cells were verified by flow cytometric analysis with anti-CD4 and anti-CD25 staining. Tregs were then cultured in RPMI 1640 FCS $(10 \%)$ overnight for recovery. The supernatants were collected for the determination of IL-10 and TGF- $\beta 1$ levels.

\section{Flow cytometric analysis}

To observe the CTLA-4 expression on the surface of Tregs, cells were stained with anti-human CTLA-4-FITC antibody 
Table 1: Patient demographics

\begin{tabular}{|c|c|c|c|c|c|}
\hline Variable & n & Age (years) & $\begin{array}{c}\text { Burn area } \\
\text { (TBSA\%) }\end{array}$ & $\begin{array}{c}\text { Average area } \\
\text { (TBSA\%) }\end{array}$ & $\begin{array}{l}\text { III }^{\circ} \text { area } \\
\text { (TBSA\%) }\end{array}$ \\
\hline Total & 106 & $33.6 \pm 4.3$ & $30-99$ & $57.4 \pm 5.6$ & $33.3 \pm 6.5$ \\
\hline Group I & 41 & $33.1 \pm 6.9$ & $30-49$ & $39.4 \pm 7.4$ & $17.4 \pm 3.9$ \\
\hline Group II & 34 & $29.3 \pm 5.1$ & $50-69$ & $57.7 \pm 10.7^{* *}$ & $32.9 \pm 6.3^{* *}$ \\
\hline Group III & 31 & $32.4 \pm 6.3$ & $70-99$ & $82.6 \pm 15.1^{\& \&}$ & $63.7 \pm 14.5^{\& \&}$ \\
\hline Sepsis & 59 & $34.3 \pm 5.5$ & $30-99$ & $67.2 \pm 11.3^{\# \#}$ & $45.3 \pm 8.6^{\# \#}$ \\
\hline Non-sepsis & 47 & $32.8 \pm 5.7$ & $30-72$ & $45.0 \pm 8.1$ & $18.2 \pm 3.8$ \\
\hline Survivors & 42 & $35.7 \pm 6.8$ & $30-88$ & $56.2 \pm 10.2^{t+}$ & $29.2 \pm 5.8^{\dagger \dagger}$ \\
\hline Non-survivors & 17 & $31.2 \pm 10.5$ & $30-99$ & $77.1 \pm 23.4$ & $55.2 \pm 16.2$ \\
\hline
\end{tabular}

Data presented as the mean \pm standard deviation or percentage. TBSA = total body surface area (range); $I I I^{\circ}$ area = third-degree burn area. Significant difference between Group II and Group I (**P<0.01); significant difference between Group II and Group III (\&\&P<0.01); significant difference between sepsis group and non-sepsis group $(\# P<0.01)$; Significant difference between survivors group and non-survivors $\left({ }^{+\dagger} P<\right.$ $0.01)$.

for 30 minutes at $4^{\circ} \mathrm{C}$ in the dark. Concomitantly, for detection of intranuclear FOXP3, cells were reacted with $1 \mathrm{ml}$ freshly prepared fixation/permeabilization working solution for two hours at $4^{\circ} \mathrm{C}$. After washing cells with one times permeabilization buffer twice, cells were stained with antihuman FOXP3-FITC antibody for 30 minutes at $4^{\circ} \mathrm{C}$ in the dark. After washing twice, cells were analyzed by flow cytometry using a FACScan (BD Biosciences, Mountain View, CA, USA). The fluorescence intensity was represented as a mean value.

\section{Cytokine measurements by ELISA}

IL-10 and TGF- $\beta 1$ levels were determined by ELISA, strictly following the protocols provided by the manufacturer. The color reaction was terminated by adding $100 \mu$ of ortho-phosphoric acid. Plates were read in a microplate reader (Spectra MR, Dynex, VA, USA). The standard concentration curves for both IL-10 and TGF- $\beta 1$ were from 0 to $2000 \mathrm{pg} / \mathrm{ml}$.

\section{SYBR green real-time RT-PCR}

Total RNA was extracted from Tregs using the single-step technique of acid guanidinium thiocyanate-chloroform extraction, according to the manufacturer's instructions. The concentration of purified total RNA was determined spectrophotometrically at $260 \mathrm{~nm}$. mRNA for IL-10 and TGF- $\beta 1$ in Tregs and GAPDH were quantified in duplicate by SYBR Green two-step, real-time RT-PCR. After the removal of potentially contaminating DNA with DNase I, 1 $\mu \mathrm{g}$ of total RNA from each sample was used for reverse transcription with an oligo dT and a Superscript II to generate first-strand cDNA. PCR reaction mixture was prepared using SYBR Green PCR Master Mix. Thermal cycling conditions were 10 minutes at $95^{\circ} \mathrm{C}$ followed by 40 cycles of $95^{\circ} \mathrm{C}$ for 15 seconds and $60^{\circ} \mathrm{C}$ for one minute on a Sequence Detection System (Applied Biosystems, Foster City, CA, USA). Each gene expression was normalized with GAPDH mRNA content. Sequences of human primer for SYBR Green PCR were shown follows: IL-10 (79 bp) AAGGCGCATGTGAACTCCC (sense), ACGGCCTTGCTCTTG TTTTC (antisense) [21]; TGF- $\beta 1$ (85 bp) TGAACCGGCCTTTCCTGCTTCTCATG (sense), GCGGAAGTCAATGTACAGCTGCCGC (antisense) [22]; GAPDH (147 bp) -ACTTCAACAGCGACACCCACT (sense), GCCAAATTCGTTGTCATACCAG (antisense) [23].

\section{Statistical analysis}

Data were expressed as mean \pm standard deviation (SD) and analyzed with analysis of variance (ANOVA; a mixedmodel, factorial ANOVA). Turkey Test was used to evaluate significant differences between groups. A $P$ value of 0.05 or less was considered to indicate statistical significance.

\section{Results}

\section{Demographics}

One hundred and six patients with burn injury were included in the present study. The patients' demographics are illustrated in Table 1. The test for homogeneity of variance was considered and the ANOVA assumption was met. The omnibus ANOVA was also found to be significant. There was no significant difference in age among the patients with different burn size. However, there were sig- 
nificant differences in burn area between Group II and Group I $(P<0.01)$. The sepsis group had markedly large burn areas compared with the non-sepsis group $(P<0.01)$. Similarly, burn area in the non-survivors was much larger than that in the survivors $(P<0.01)$.

\section{Isolation of $\mathrm{CD}^{+}{ }^{+} \mathrm{CD} 25^{+}$Tregs}

$\mathrm{CD} 4{ }^{+} \mathrm{CD} 25^{+}$Tregs were isolated from the peripheral blood lymphocytes in two steps by a magnetic cell sorting (MACS) system. As shown in Figure 1, the purity of positively sorted $\mathrm{CD} 4{ }^{+} \mathrm{CD} 25^{+}$Tregs was $93.5 \pm 1.7 \%$ with the survival rate of $96.2 \pm 2.9 \%$. The purity of negatively sorted CD4 ${ }^{+} \mathrm{CD} 25-\mathrm{T}$ cells was $89.6 \pm 2.5 \%$.

\section{The phenotypic changes in Tregs after burns}

To investigate the changes in Treg phenotypes, these cells were analyzed at different time points and in different groups after burns. A three (Group) times five (Day) mixed-model, factorial ANOVA was conducted. As shown in Figure 2, increased expressions of CTLA-4 and FOXP3 were found to be enhanced on the surface of Tregs from burned patients on PBD 1 to 21 compared with normal controls, and there were obvious differences among patients with various burn sizes $(P<0.05$ or $P<0.01)$. The expressions of CTLA-4 and FOXP3 were significantly higher in patients with serious burns at all time points, and they were even higher in septic patients than those without sepsis on PBD 3 to $21(P<0.01)$. Among septic patients, the expressions of CTLA-4 and FOXP3 in the survival group were significantly lower than those with fatal outcome on PBD 3 to $21(P<0.05$ or $P<0.01)$.

\section{Changes in protein and gene levels of cytokines released by Tregs}

The capacity of Tregs to produce IL-10 and TGF- $\beta 1$, which are two of the markers of function of Tregs, was analyzed in
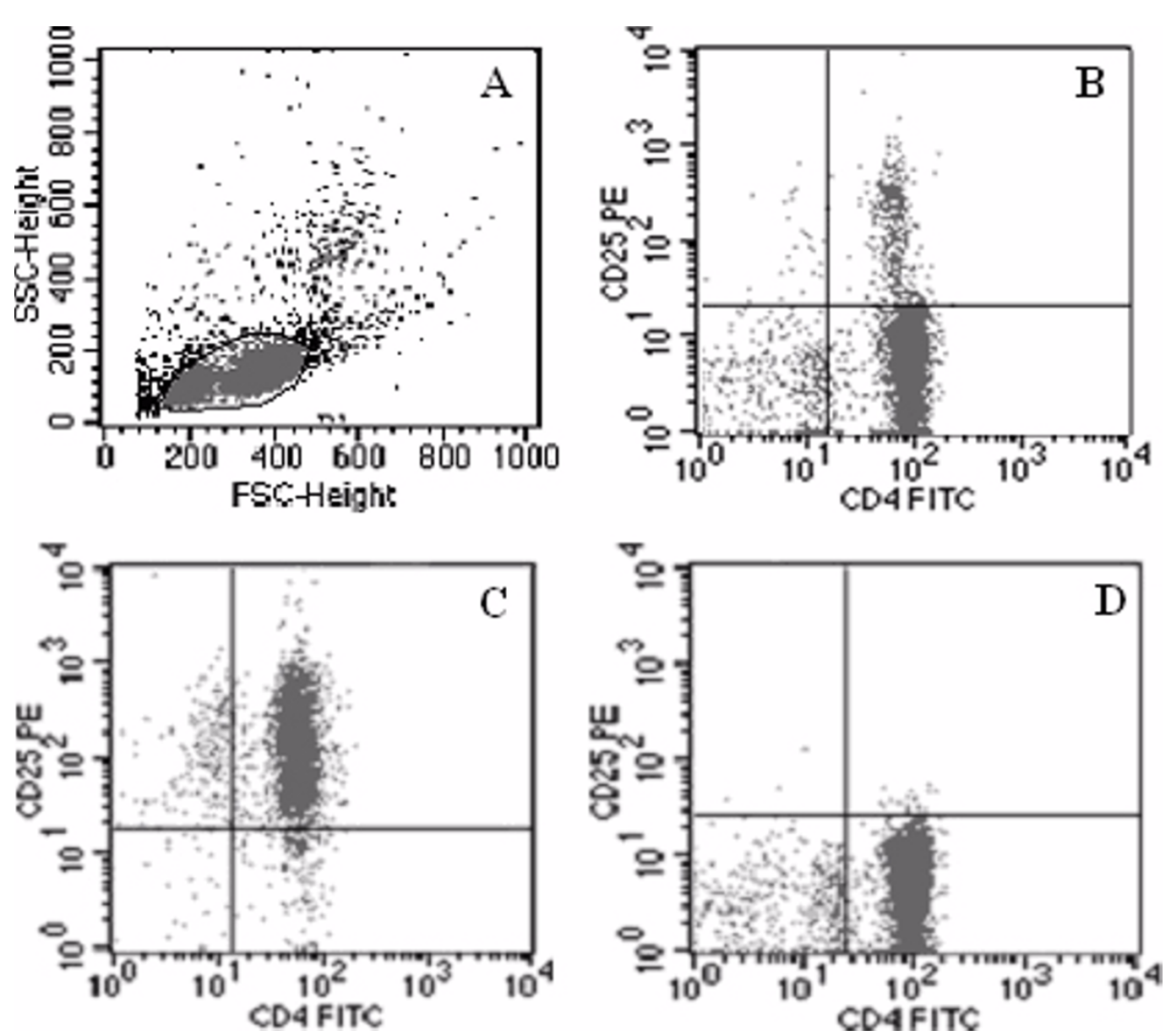

Figure 1 Isolation of $\mathrm{CD} 4{ }^{+} \mathrm{CD} 25^{+}$Tregs from the peripheral blood lymphocytes. CD4+CD25+regulatory T cells (Tregs) were isolated from the peripheral blood lymphocytes in two steps by magnetic cell sorting (MACS) system according to manufacturer's instructions. (a) T lymphocytes before isolation and (b) CD4+T cells are shown. (c) The purity of positively sorted CD4+CD25+ Tregs was $93.5 \pm 1.7 \%$ with the survival rate of $96.2 \pm 2.9 \%$. (d) The purity of negatively sorted CD4+CD25-T cells was $89.6 \pm 2.5 \%$. 

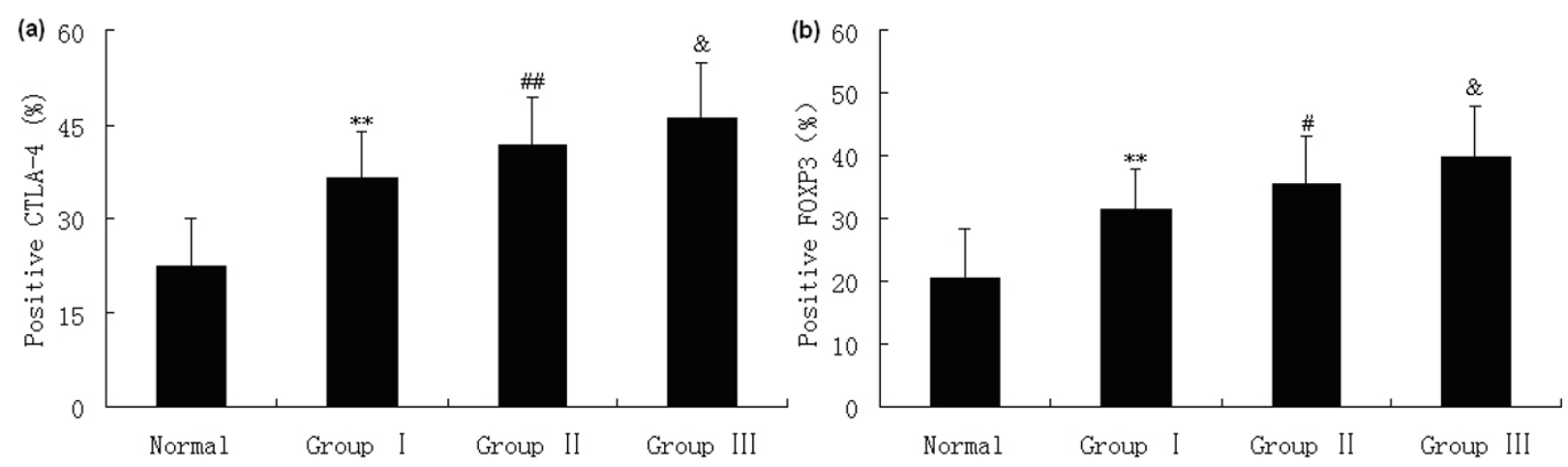

(c)

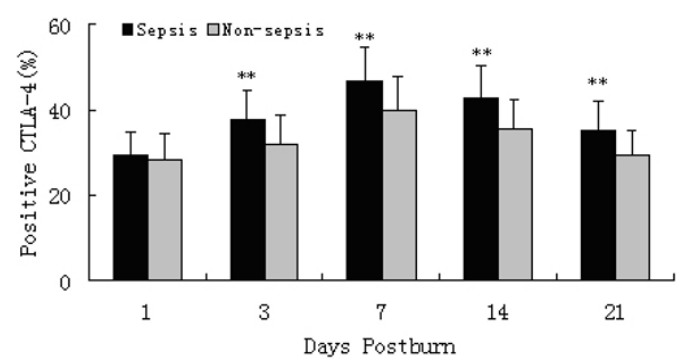

(e)

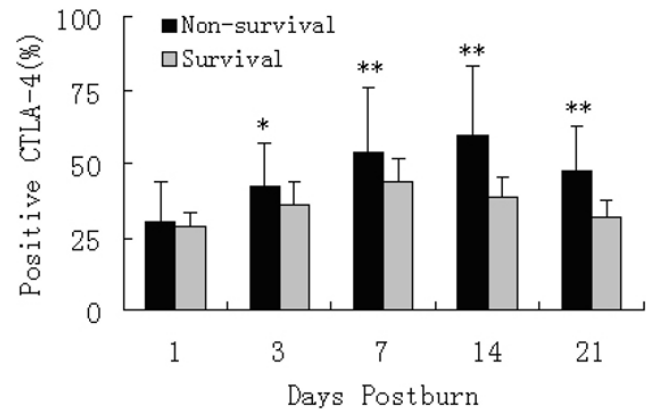

(d)

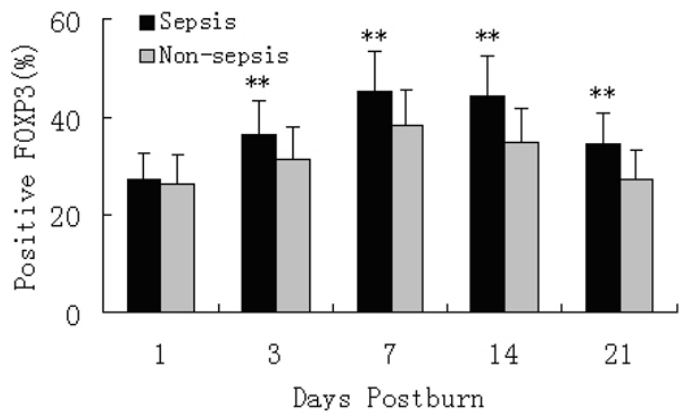

(f)

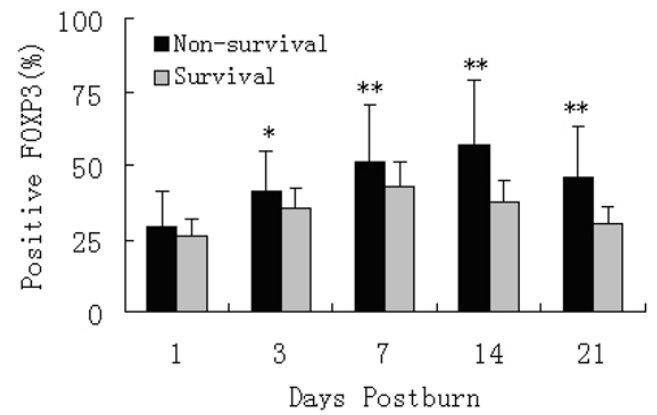

Figure 2 Flow cytometric analysis of phenotypes of Tregs. Increased expressions of CTLA-4 and FOXP3 on the surface of regulatory T cells (Tregs) from burned patients were found on postburn days (PBD) 1 to 21 compared with normal controls, and there were obvious differences among patients with various burn sizes (( $\mathbf{a}$ and $\mathbf{b})$ a mean of all days). The expressions of CTLA-4 and FOXP3 were significantly higher in patients with serious burns during the whole observational period, and (c and d) they were much higher in septic patients than those without sepsis on PBD 3 to 21. (e and f) Among septic patients, the expressions of CTLA-4 and FOXP3 in the survival group were obviously lower than those in non-survival group on PBD 3 to $21 .{ }^{*} P<0.05, * * P<0.01$, Group I vs. normal group or sepsis group vs. non-sepsis group or non-survivors vs. survivors; $\# P<0.05, \# \# P<0.01$, Group II vs. Group I; \&P<0.05, Group III vs. Group II.

the present experiment. As shown in Figures 3 and 4, elevated protein and gene expressions of IL-10 and TGF- $\beta 1$ in Tregs from burned patients were detected on PBD 1 to 21 in comparison with normal controls, and there were marked differences among patients with different extents of burn injury $(P<0.05$ or $P<0.01)$. The protein and gene expressions of IL-10 and TGF- $\beta 1$ in Tregs were significantly higher in septic patients than those without sepsis on PBD 3 to $21(P<0.05$ or $P<0.01)$. Among septic patients, the expression levels of IL-10 and TGF- $\beta 1$ in the survival group were obviously lower than those with non-survival group on PBD 3 to $21(P<0.05$ or $P<0.01)$.

\section{Discussion}

Severe burn injury induces detrimental changes in immune function, often leaving the host highly susceptible to developing life-threatening opportunistic infections. Advances in our understanding of how burn influences host immune response suggest that thermal injury causes a phenotypic imbalance in the regulation of Th1- and Th2-type immune responses [24]. The immune response to infection repre- 


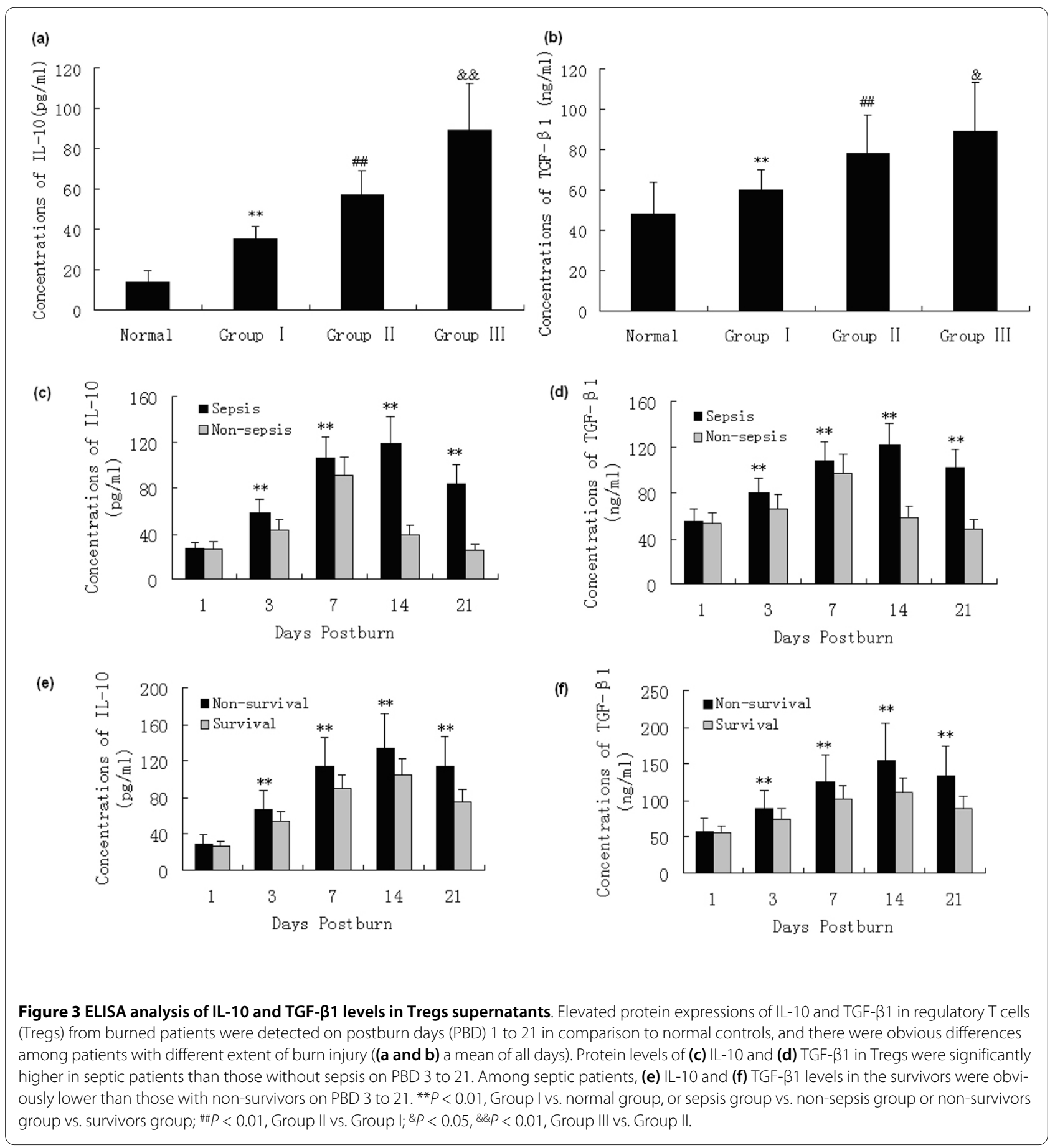

sents a complex balance between the successful induction of proinflammatory antipathogen response and anti-inflammatory response required to limit damage to host tissues. The vast majority of clinical and basic science research on the immune consequences of burn injury and sepsis conducted during the past three decades has focused mainly on the roles of macrophages, neutrophils, and, to a lesser extent, conventional T lymphocytes [25,26]. During recent years, however, it has become increasingly clear that minor subsets of innate immune cells, innate regulatory lymphocytes in particular, are central to processes involved in both protective immunity and immunopathology [27]. Tregs undoubtedly play an important role in controlling this balance during infection, and the results can range from highly detrimental to the host to highly beneficial to both the host and pathogen [28].

In our previous observations, significant proliferation of splenic T cells and IL-2 as well as IL-2R $\alpha$ expression on T 

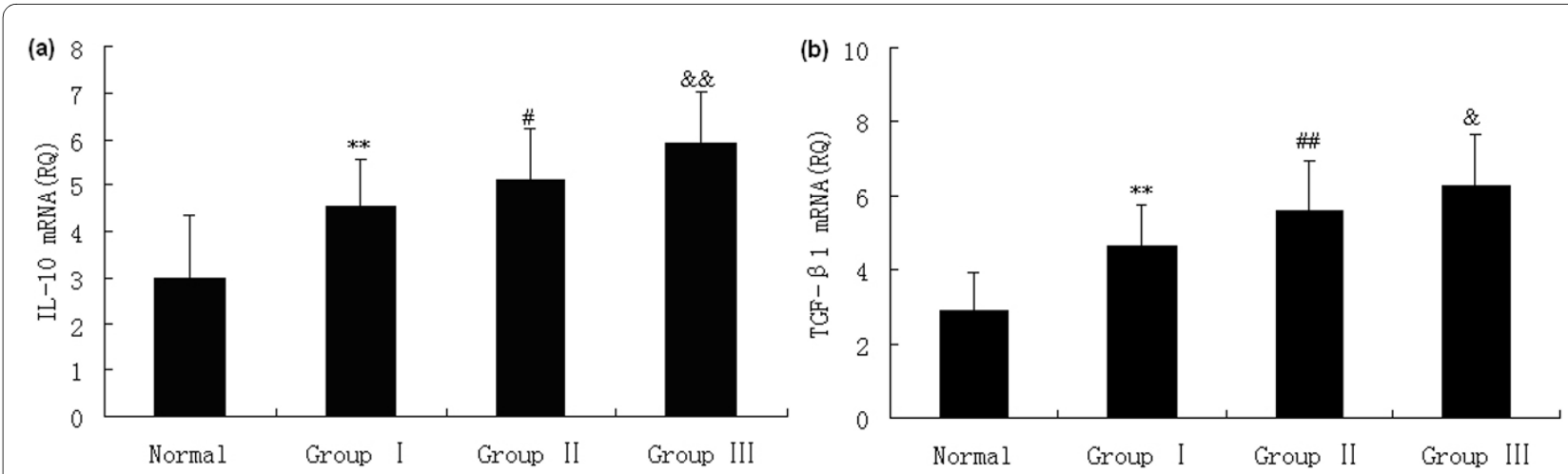

(c)

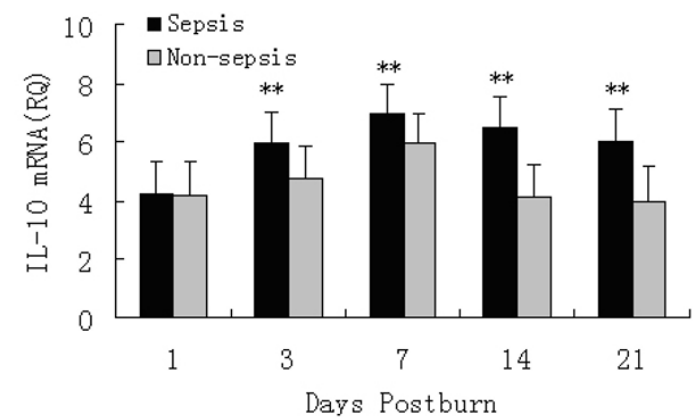

(e)

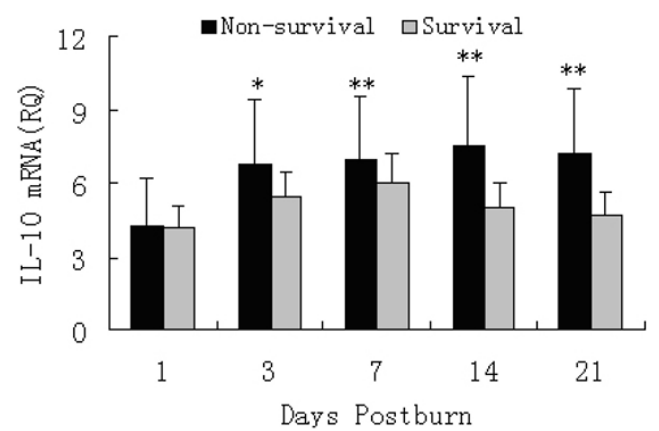

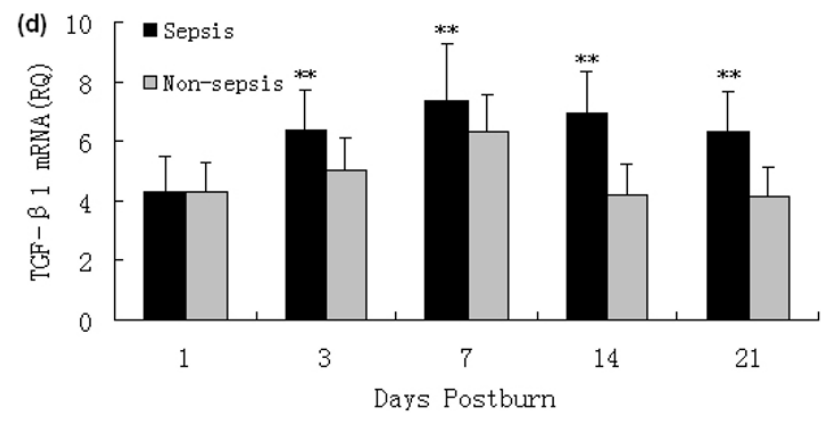

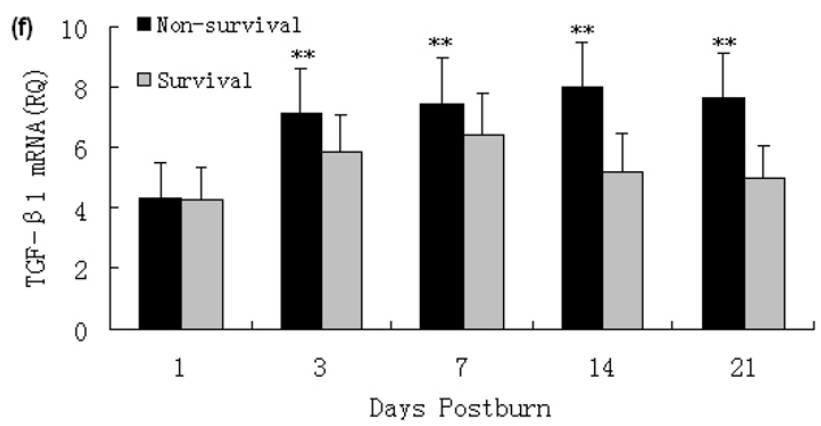

Figure 4 SYBR green real-time RT-PCR analysis for mRNA expression of IL-10 and TGF- $\boldsymbol{\beta} 1$ in Tregs. Enhanced gene expressions of (a) IL-10 and (b) TGF- $\beta 1$ in regulatory T cells (Tregs) from burned patients were detected on postburn days (PBD) 1 to 21 in comparison with normal controls, and there were obvious differences among patients with different extent of burn injury. mRNA expressions of (c) IL-10 and (d) TGF- $\beta 1$ in Tregs were significantly higher in septic patients than those without sepsis on PBD 3 to 21 . Among septic patients, (e) IL-10 and (f) TGF- $\beta 1$ mRNA expressions in the survival group were markedly lower than those with fatal outcome on PBD 3 to 21 . ${ }^{*} P<0.01$, ${ }^{* *} P<0.01$, Group I vs. normal group or sepsis group vs. non-sepsis group, or non-survivors group vs. survivors group; $\# P<0.01, \# P<0.01$, Group II vs. Group I; \&P< 0.05, \&\&P<0.01, Group III vs. Group II.

cells were simultaneously suppressed to a certain extent on PBD 1 to 7 in rats [29]. Nuclear factor of activated T cell activity of splenic $\mathrm{T}$ cells was markedly down-regulated on PBD 1 to 3 . It was revealed that $\mathrm{T}$ cells were polarized to Th2 cells after burn injury. These data indicate that there is a marked suppression of $\mathrm{T}$ cell function following major burns. To collaborate with other findings, it has been reported that Tregs in mice can inhibit the proliferation of $\mathrm{T}$ cell and release of cytokine for polarization to antigen-spe- cific Th1 cells after acute insults [30]. Similarly, we recently reported increased Treg activity after thermal injury in rats [31]. Because severe burn injury triggers both excessive inflammation and suppressed adaptive immunity, we would expect that there might be an activation of immune activity of Tregs isolated from burn-injury patients. Therefore, a major objective of this study was to define how thermal injury influenced the maturation of Tregs in peripheral blood in severely burned patients. We 
considered that this is an important question to be addressed as regulation of Th1- and Th2-type responses against infectious pathogens by Tregs can markedly affect host survival [30].

In the current study, increased expressions of CTLA-4 and FOXP3 on the surface of Tregs from burned patients were observed on PBD 1 to 21 compared with normal controls. This finding was consistent with a previous report that was published prior to the identification of Tregs [32]. In that study, the authors demonstrated that cell-surface CD25 expression on $\mathrm{CD}^{+} \mathrm{T}$ cells increased by five days after injury and remained elevated for at least two weeks. Meantime, it was presumed the increase in $\mathrm{CD} 25$ expression was due to injury-induced $\mathrm{CD}^{+} \mathrm{T}$ cell activation. However, we demonstrate here that the increased percentage of circulating Tregs in our burned patients was attributable to both T cell activation and a significant increase in the percentage of $\mathrm{CD}^{+} \mathrm{CD} 25^{\text {high }}$ cells. This increase in circulating $\mathrm{CD}^{+} \mathrm{CD} 25^{\text {high }} \mathrm{T}$ cells may represent Tregs expansion or possibly migration of these cells from immunologically active sites instigated by the injury. These are important mechanistic issues that can be studied in more detail using animal models of injury.

Numerous studies have shown that an increased burn size leads to increased mortality in burn patients $[12,33]$. In a large prospective clinical trial, Jeschke has indicated that different burn sizes are associated with differences in intensity of inflammation, in body composition, in protein synthesis, and in organ function. In the present study in vivo, we found there were obvious differences in the expressions of CTLA-4 and FOXP3 on the surface of Tregs among patients with various burn sizes. Taken together, these data suggest that acute insults can induce or amplify $\mathrm{CD}^{+}{ }^{+} \mathrm{CD} 25^{+}$Tregs function and that $\mathrm{CD} 4{ }^{+} \mathrm{CD} 25^{+} \mathrm{T}$ cells contribute to the development of postinjury immunosuppression.

Using a mouse burn injury model, Ni Choileain noticed that injury per se significantly enhances Tregs function [33]. Such increase in Tregs activity was apparent on day 7 after injury and was restricted to $\mathrm{CD} 4{ }^{+} \mathrm{CD} 25^{+} \mathrm{T}$ cells in lymph nodes draining the injury site. Moreover, our recent report implicated that the injury-induced increase in Tregs activity was cell-contact dependent and was mediated in part by increased cell surface TGF- $\beta 1$ expression [31]. Depending on the different settings, cytokines (including TGF- $\beta 1$ and IL-10) as well as direct cell killing of conventional $\mathrm{T}$ cells and antigen presenting cells (APCs) by the Tregs have been proposed as the one of the mechanism of immunosuppression [34-36]. Similarly, our results in this study showed that gene/protein expression of IL-10 and TGF- $\beta 1$ in Tregs from burn patients was augmented on PBD 1-21 in comparison to normal controls, and there were obvious differences among patients with different extent of burn injury. It appears that serious burn injury induces activitiy of Tregs resulting in high expressions of certain phenotypes, and this enhanced Tregs activity might play a key role in modulating cell-mediated immunity of $\mathrm{T}$ lymphocytes.

Sepsis and subsequent multiple organ dysfunction syndrome are frequent complications of major trauma or burns, and remain to be the most common cause of morbidity as well as mortality in critical illnesses. It is well known that marked immune depression is critically involved in the development of sepsis. Immunoparalysis has recently be thought to be a possible cause of explaining the failure of numerous clinical therapeutic trials in septic shock [37]. Severe burn injury induced a marked reduction in HLA-DR expression at both protein and messenger RNA levels [38]. Its persistent decrease was associated with mortality and the development of septic complications [39]. However, whether sepsis and mortality after burns are due to inflammation, immune suppression or other pathophysiologic contributing factors is not entirely elucidated. Furthermore, it is also not very clear whether Tregs induced by severe burns can contribute to the development of sepsis and outcome of the patients.

The studies presented here described that the expressions of activation markers of Tregs and cytokines produced by Tregs were significantly higher in patients with serious burns at all time points, and they were much higher in septic patients than those without sepsis on PBD 3 to 21 . Among septic patients, the expressions of these parameters in the survival group were markedly lower than those with fatal outcome on PBD 3 to 21. These findings support the concept that $\mathrm{CD} 4{ }^{+} \mathrm{CD} 25^{+}$Tregs contribute to the control of immune response after being affected by thermal injury and sepsis. The persistence of a pronounced immunoparalysis induced by Tregs after severe sepsis is associated with a poor outcome after burns. Recently, similar findings have been reported by others [40-42]. Some authors suggest that although $\mathrm{CD} 4{ }^{+} \mathrm{CD} 25^{+}$Tregs induced by IL-10 seem to contribute to sepsis-induced suppression of lymphoid dependent immunity, the removal of $\mathrm{CD} 25^{+}$cells does not provide a survival advantage or disadvantage.

We therefore speculated that Tregs might also play an essential role in initiating effective immunosuppression response to sepsis. This may be related to their ability to interact with components of the innate and adaptive immune response, and to their potentiality to be activated nonspecifically by bacterial products and/or cytokines, and to regulate through direct cell-cell and/or soluble mediators. It is our hope that a better understanding of the mechanism through which those rare lymphocyte subsets, which is found to exert such a profound effect on the immune response, may help in improving our clinical ability not only in diagnosis but also in treatment for the critically septic individual. 


\section{Conclusions}

In summary, severe burn injury per se could result in activation and maturation of Tregs, thus invoking its immunodepressive activity to the full extent, finally leading to immunosuppression. Elevated levels of cytokines produced by Tregs and activation markers on Tregs surface might play an important role in the pathogenesis of sepsis and mortality in burned patients.

\section{Key messages}

- Severe burn played an important role in activation and expansion of Treg cells. This feature might allow Treg to function for a prolonged period of time to regulate immune responses and induce suppression of $\mathrm{T}$ lymphocyte immune function.

- The elevated levels of cytokines producted by Treg and activation markers on Treg surface may also be involved in increased burn sizes, sepsis and mortality of burned patients.

- This suggested that Treg might have a potential for suppressing the proliferation and cytokine production of $\mathrm{T}$ cells in vivo. It also suggested that the regulation of Treg cells as a cellular therapy might be important to the Th1/Th2 cytokine balance in burned patients and sepsis patients.

\begin{abstract}
Abbreviations
ANOVA: analysis of variance; bp: base pair; CTLA-4: cytotoxic T-lymphocyteassociated antigen 4; ELISA: enzyme-linked immunosorbent assay; FCS: fetal calf serum; FITC: fluorescein isothiocyanate; FOXP3: the forkhead/winged helix transcription factor p3; IL: interleukin; MACS: magnetic cell sorting; PBD: postburn days; RT-PCR: reverse transcription polymerase chain reaction; SD: standard deviation; TBSA: total body surface area; TGF- $\beta 1$ : transforming growth factor- $\beta 1$; Tregs: regulatory $T$ cells.
\end{abstract}

\section{Competing interests}

The authors declare that they have no competing interests.

\section{Authors' contributions}

YMY supervised the entire project and wrote the manuscript with LFH and with comments from all coauthors. LFH and ZYS participated in the study design. LFH, YMY, YY, and LXH conducted the clinical study. ND processed the data analysis. All authors read and approved the final manuscript.

\section{Acknowledgements}

This work was supported, in part, by grants from the National Basic Research Program of China (No. 2005CB522602), the National Natural Science Foundation (No. 30872683, 30901561), and the National Natural Science Outstanding Youth Foundation of China (No. 30125020).

\section{Author Details}

Department of Microbiology and Immunology, Burns Institute, First Hospital Affiliated to the Chinese PLA General Hospital, 51 Fu-cheng Road, Haidian District, Beijing 100048, PR China

Received: 3 September 2009 Revisions Requested: 5 November 2009 Revised: 2 December 2009 Accepted: 11 January 2010 Published: 11 January 2010

\section{References}

1. Sakaguchi S: Naturally arising CD4+ regulatory T cells for immunologic self-tolerance and negative control of immune responses. Annu Rev Immunol 2004, 22:531-562.
2. Roncarolo MG, Bacchetta R, Bordignon C, Narula S, Levings MK: Type 1 T regulatory cells. Immunol Rev 2001, 182:68-79.

3. Zhai Y, Kupiec-Weglinski JW: What is the role of regulatory T cells in transplantation tolerance? Curr Opin Immunol 1999, 11:497-503.

4. Shevach EM: CD4+CD25+ suppressor T cells: more questions than answers. Nat Rev Immunol 2002, 2:389-400.

5. Ramsdell F: Foxp3 and natural regulatory T cells: key to a cell lineage? Immunity 2003, 19:165-168.

6. Morgan ME, van Bilsen JH, Bakker AM, Heemskerk B, Schilham MW Hartgers FC, Elferink BG, Zanden L van der, de Vries RR, Huizinga TW, Ottenhoff TH, Toes RE: Expression of FOXP3 mRNA is not confined to CD4+CD25+ T regulatory cells in humans. Hum Immunol 2005, 66:13-20.

7. Finnerty CC, Herndon DN, Przkora R, Pereira CT, Oliveira HM, Queiroz DM, Rocha AM, Jeschke MG: Cytokine expression profile over time in severely burned pediatric patients. Shock 2006, 26:13-19.

8. O'Garra A, Vieira PL, Vieira P, Goldfeld AE: IL-10-producing and naturally occurring CD4+ Tregs: limiting collateral damage. J Clin Invest 2004, 114:1372-1378

9. Venet F, Chung CS, Kherouf H, Geeraert A, Malcus C, Poitevin F, Bohé J Lepape A, Ayala A, Monneret G: Increased circulating regulatory T cells (CD4(+)CD25 (+)CD127 (-)) contribute to lymphocyte anergy in septic shock patients. Intensive Care Med 2009, 35:678-686.

10. Belkaid Y, Rouse BT: Natural regulatory T cells in infectious disease. Nat Immunol 2005, 6:353-360.

11. Efron P, Moldawer LL: Sepsis and the dendritic cell. Shock 2003, 20:386-401

12. Peden M, McGee K, Sharma G: The injury chart book: a graphical overview of the global burden of injuries. Geneva: World Health Organization; 2002:29.

13. Pereira CT, Barrow RE, Sterns AM, Hawkins HK, Kimbrough CW, Jeschke MG, Lee JO, Sanford AP, Herndon DN: Age-dependent differences in survival after severe burns: a unicentric review of 1,674 patients and 179 autopsies over 15 years. J Am Coll Surg 2006, 202:536-548.

14. Mannick JA, Rodrick ML, Lederer JA: The immunologic response to injury. J Am Coll Surg 2001, 193:237-244.

15. Shelley OT, Murphy H, Paterson JA, Mannick JA: Interaction between the innate and adaptive immune systems is required to survive sepsis and control inflammation after injury. Shock 2003, 20:123.

16. Roncarolo MG, Gregori S, Levings M: Type $1 \mathrm{~T}$ regulatory cells and their relationship with CD4+CD25+T regulatory cells. Novartis Found Symp 2003, 252:115-127. discussion 127-131, 203-21017.Yende S, Kellum JA: Understanding genetics of sepsis: will new technology help? Crit Care 2009, 13:141-.

18. Venet F, Bohé J, Debard AL, Bienvenu J, Lepape A, Monneret G: Both percentage of gammadelta T lymphocytes and CD3 expression are reduced during septic shock. Crit Care Med 2005, 33:2836-2840.

19. O'Brien JM Jr, Ali NA, Abraham E: Year in review 2007: Critical Care-multiple organ failure and sepsis. Crit Care 2008, 12:228-

20. Greenhalgh DG, Saffle JR, Holmes JH, Gamelli RL, Palmieri TL, Horton JW, Tompkins RG, Traber DL, Mozingo DW, Deitch EA, Goodwin CW, Herndon DN, Gallagher JJ, Sanford AP, Jeng JC, Ahrenholz DH, Neely AN, O'Mara MS, Wolf SE, Purdue GF, Garner WL, Yowler CJ, Latenser BA: American Burn Association consensus conference to define sepsis and infection in burns. J Burn Care Res 2007, 28:776-790.

21. Kurokawa CS, Araujo JP Jr, Soares AM, Sugizaki MF, Peraçoli MT: Pro- and anti-inflammatory cytokines produced by human monocytes challenged in vitro with Paracoccidioides brasiliensis. Microbiol Immunol 2007, 51:421-428.

22. Rostkowska-Nadolska B, Kapral M, Mazurek U, Gawron W, Preś K: Coexpression of the TGF-beta1 and TGF- beta2 isoforms in nasal polyps and in healthy mucosa. Postepy Hig Med Dosw (Online) 2007, 61:702-707.

23. Lyng MB, Laenkholm AV, Pallisgaard N, Ditzel HJ: Identification of genes for normali zation of real-time RT-PCR data in breast carcinomas. BMC Cancer 2008, 8:20-

24. Guo Z, Kavanagh E, Zang Y, Dolan SM, Kriynovich SJ, Mannick JA, Lederer JA: Burn Injury promotes antigen-driven Th2-type responses in vivo. J Immunol 2003, 171:3983-3990.

25. Zhang LT, Yao YM, Lu JQ, Yan XJ, Yu Y, Sheng ZY: Recombinant bactericidal/permeability- increasing protein inhibits endotoxininduced high-mobility group box 1 protein gene expression in sepsis. Shock 2008, 29:278-284. 
26. Huang LF, Yao YM, Meng HD, Zhao XD, Dong N, Yu Y, Sheng ZY: The effect of high mobility group box-1 protein on immune function of human T lymphocytes in vitro. Zhongguo Wei Zhong Bing Ji Jiu Yi Xue 2008, 20:7-13.

27. Schneider DF, Glenn CH, Faunce DE: Innate lymphocyte subsets and their immunoregulatory roles in burn injury and sepsis. J Burn Care Res 2007, 28:365-379.

28. MacConmara MP, Maung AA, Fujimi S, McKenna AM, Delisle A, Lapchak PH, Rogers S, Lederer JA, Mannick JA: Increased CD4+ CD25+ T regulatory cell activity in trauma patients depresses protective Th1 immunity. Ann Surg 2006, 244:514-523.

29. Zhang LT, Yao YM, Dong Ning Dong YQ, Yu Y, Sheng ZY: Relationship between high mobility group box-1 protein release and T cell suppression in rats after thermal injury. Shock 2008, 30:449-455.

30. Murphy TJ, Ni Choileain N, Zang Y, Mannick JA, Lederer JA: CD4+CD25+ regulatory $\mathrm{T}$ cells control innate immune reactivity after injury. $J$ Immunol 2005, 174:2957-2963.

31. Huang LF, Yao YM, Zhang LT, Dong N, Yu Y, Sheng ZY: The effect of high mobility group box-1 protein on activity of regulatory $T$ cells after thermal injury in rats. Shock 2009, 31:322-329.

32. Walsh DS, Siritongtaworn P, Pattanapanyasat $K$, Thavichaigarn $P$, Kongcharoen P, Jiarakul N, Tongtawe P, Yongvanitchit K, Komoltri C, Dheeradhada C, Pearce FC, Wiesmann WP, Webster HK: Lymphocyte activation after non-thermal trauma. Br J Surg 2000, 87:223-230.

33. Ni Choileain N, MacConmara M, Zang Y, Murphy TJ, Mannick JA, Lederer JA: Enhanced regulatory T cell activity is an element of the host response to injury. J Immunol 2006, 176:225-236.

34. Marie JC, Letterio JJ, Gavin M, Rudensky AY: TGF- $\beta 1$ maintains suppressor function and Foxp3 expression in $C D 4+C D 25+$ regulatory $T$ cells. J Exp Med 2005, 201:1061-1067.

35. Pestka S, Krause CD, Sarkar D, Walter MR, Shi Y, Fisher PB: Interleukin-10 and related cytokines and receptors. Annu Rev Immunol 2004, 22:929-979.

36. Zhang Y, Yao YM, Yu Y, Wu Y, Sheng ZY: Influence of high mobility group box-1 protein on the correlation between regulatory T cells and CD4+ CD25- T cells of spleen in mice. Zhonghua Wai Ke Za Zhi 2008, 46:217-220.

37. Monneret G, Debard AL, Venet F, Bohe J, Hequet O, Bienvenu J, Lepape A: Marked elevation of human circulating CD4+CD25+ regulatory T cells in sepsis-induced immunoparalysis. Crit Care Med 2003, 31:2068-2071.

38. Dong N, Yao YM, Cao YJ, He LX, Chai JK, Xu S, Sheng ZY: Clinical significance of changes in quantitative expression of human leukocyte antigen DR in severely burned patients. Zhonghua Wai Ke Za Zhi 2007, 45:766-769.

39. Venet F, Tissot $S$, Debard AL, Faudot $C$, Crampé C, Pachot A, Ayala A, Monneret G: Decreased monocyte human leukocyte antigen-DR expression after severe burn injury: Correlation with severity and secondary septic shock. Crit Care Med 2007, 35:1910-1917.

40. Dong N, Yao YM, Cao YJ, He LX, Yu Y, Chai JK, Sheng ZY: The clinical significance of changes in immunological function of T lymphocyte in severe burn patients with sepsis. Zhonghua Shao Shang Za Zhi 2007, 23:84-87.

41. Venet F, Chung CS, Monneret G, Huang X, Horner B, Garber M, Ayala A: Regulatory T cell populations in sepsis and trauma. J Leukoc Biol 2008 83:523-535.

42. Wisnoski N, Chung CS, Chen Y, Huang X, Ayala A: The contribution of CD4+ CD25+ T-regulatory-cells to immune suppression in sepsis. Shock 2007, 27:251-257.

\section{doi: $10.1186 / \mathrm{cc} 8232$}

Cite this article as: Huang et al., Association between regulatory $T$ cell activity and sepsis and outcome of severely burned patients: a prospective, observational study Critical Care 2010, 14:R3 